\title{
BMJ
}

\section{Management of severe sepsis in patients admitted to Asian intensive care units: prospective cohort study}

\author{
Jason Phua, consultant, ${ }^{1}$ Younsuck Koh, professor, ${ }^{2}$ Bin Du, professor, ${ }^{3}$ Yao-Qing Tang, professor, ${ }^{4}$ Jigeeshu V \\ Divatia, professor, ${ }^{5}$ Cheng Cheng Tan, consultant, ${ }^{6}$ Charles D Gomersall, professor, ${ }^{7}$ Mohammad Omar Faruq, \\ professor, ${ }^{8}$ Babu Raja Shrestha, consultant, ${ }^{9}$ Nguyen Gia Binh, consultant, ${ }^{10}$ Yaseen M Arabi, associate \\ professor, ${ }^{11}$ Nawal Salahuddin, associate professor, ${ }^{12}$ Bambang Wahyuprajitno, consultant, ${ }^{13}$ Mei-Lien Tu, \\ respiratory therapist, ${ }^{14}$ Ahmad Yazid Haji Abd Wahab, consultant, ${ }^{15}$ Akmal A Hameed, consultant, ${ }^{16}$ Masaji \\ Nishimura, professor, ${ }^{17}$ Mark Procyshyn, respiratory therapist, ${ }^{18}$ Yiong Huak Chan, biostatistician ${ }^{19}$ for the \\ MOSAICS Study Group
}

\section{${ }^{1}$ Division of Respiratory and Critical Care Medicine, Department of Medicine, National University Hospital, National University Health System Tower Block, Level 10, 1E Kent Ridge Road, Singapore 119228 \\ ${ }^{2}$ Department of Pulmonary and Critical Care Medicine, Asan Medical Center, University of \\ Ulsan College of Medicine, 388-1 \\ Pungnap Dong Songpa Ku, Seoul, 138-736, Korea}

${ }^{3}$ Department of Critical Care Medicine, Peking Union Medical

College Hospital, 1 Shuai Fu Yuan, Beijing 100730, China

${ }^{4}$ Surgical Intensive Care Unit, Ruiijin Hospital, Shanghai Jiaotong University Medical School, 197 Ruiijin 2nd Road, Shanghai 200025, China

${ }^{5}$ Department of Anaesthesia, Critical Care and Pain, Tata Memorial Hospital, Dr E Borges Marg, Parel, Mumbai 400012 .

India

${ }^{6}$ Department of Anaesthesia and Intensive Care, Sultanah Aminah Hospital, Jalan Abu Bakar, 80100 Johor Bahru, Johor, Malaysia

${ }^{7}$ Department of Anaesthesia and Intensive Care, Chinese University of Hong Kong, Prince of Wales

Hospital, Ngan Shing Street, Shatin, Hong Kong

${ }^{8}$ Department of Critical Care Medicine, BIRDEM Hospital, 122 Kazi Nazrul Islam Avenue, Shah Bag, Dhaka 1000, Bangladesh

${ }^{9}$ Department of Anesthesia and Intensive Care, Kathmandu Medical College Teaching Hospital, PO Box 21266, Kathmandu, Nepal

${ }^{10}$ Intensive Care Department, Bach Mai Hospital, 78 Giai Phong, Dong Da, Hanoi, Vietnam

\section{ABSTRACT}

Objectives To assess the compliance of Asian intensive care units and hospitals to the Surviving Sepsis Campaign's resuscitation and management bundles. Secondary objectives were to evaluate the impact of compliance on mortality and the organisational characteristics of hospitals that were associated with higher compliance.

Design Prospective cohort study.

Setting 150 intensive care units in 16 Asian countries.

Participants 1285 adult patients with severe sepsis admitted to these intensive care units in July 2009. The organisational characteristics of participating centres, the patients' baseline characteristics, the achievement of targets within the resuscitation and management bundles, and outcome data were recorded.

Main outcome measure Compliance with the Surviving Sepsis Campaign's resuscitation (six hours) and management (24 hours) bundles.

Results Hospital mortality was 44.5\% (572/1285). Compliance rates for the resuscitation and management bundles were $7.6 \%$ (98/1285) and 3.5\% (45/1285), respectively. On logistic regression analysis, compliance with the following bundle targets independently predicted decreased mortality: blood cultures (achieved in $803 / 1285 ; 62.5 \%, 95 \%$ confidence interval $59.8 \%$ to $65.1 \%$ ), broad spectrum antibiotics (achieved in 821/ $1285 ; 63.9 \%, 61.3 \%$ to $66.5 \%)$, and central venous pressure (achieved in 345/870; 39.7\%, 36.4\% to 42.9\%). High income countries, university hospitals, intensive care units with an accredited fellowship programme, and surgical intensive care units were more likely to be compliant with the resuscitation bundle.

Conclusions While mortality from severe sepsis is high, compliance with resuscitation and management bundles is generally poor in much of Asia. As the centres included in this study might not be fully representative, achievement rates reported might overestimate the true degree of compliance with recommended care and should be interpreted with caution. Achievement of targets for blood cultures, antibiotics, and central venous pressure was independently associated with improved survival.

\section{INTRODUCTION}

Severe sepsis is a prevalent, costly, and often fatal condition. ${ }^{12}$ To improve outcomes in severe sepsis, the Surviving Sepsis Campaign recommends a six hour resuscitation bundle, ${ }^{3}$ including early blood cultures and antibiotics ${ }^{4}$ and various aspects of early goal directed treatment for haemodynamic derangements. ${ }^{5}$ A 24 hour management bundle is also recommended, which includes low dose steroids, ${ }^{6}$ drotrecogin alfa (activated), ${ }^{7}$ glucose control, ${ }^{8}$ and guidelines on ventilatory support. ${ }^{9}$ Several single and multicentre studies and a meta-analysis have suggested that compliance with these recommendations can benefit survival. ${ }^{10-17}$

Whether Asian intensive care units and emergency departments follow the sepsis bundles is unknown. Adherence to guidelines is often poor. ${ }^{18}$ National efforts to promote the Surviving Sepsis Campaign guidelines do not exist in most of Asia, where cost concerns limit the ability to implement potentially expensive bundles, ${ }^{1920}$ and, at least in some countries, intensive care is underdeveloped. ${ }^{21}$ To complicate matters, several papers have questioned the purported benefits of the recommended interventions, ${ }^{22-24}$ and recently revised Surviving Sepsis Campaign guidelines have toned down the recommendations for steroids, drotrecogin alfa, and glucose control. ${ }^{2526}$

With the above considerations in mind, we assessed compliance of Asian intensive care units and hospitals with the recommendations within the resuscitation and management bundles. We also evaluated the impact of compliance on mortality and the organisational characteristics of Asian hospitals that were associated with higher compliance. 
${ }^{11}$ Intensive Care Department, King Saud Bin Abdulaziz University for Health Sciences, King Abdulaziz Medical City, ICU 1425,

PO Box 22490, Riyadh, 11426, Kingdom of Saudi Arabia

${ }^{12}$ Pulmonary and Critical Care, Department of Medicine, Aga Khan University and Hospital, Stadium Road, Karachi 74800, Pakistan

${ }^{13}$ Department of Anesthesiology and Reanimation, Faculty of

Medicine - University of Airlangga, Intensive Care Unit, Dr Soetomo General Hospital, Jl Mayjen Prof Dr Moestopo 6-8, Surabaya 60285, Indonesia

${ }^{14}$ Chang Gung Memorial Hospital Kaohsiung Medical Center, Department of Respiratory

Therapy, Chang Gung Institute of Technology, No 123, Ta-Pei Road, Niao-Sung Hsiang, Kaohsiung

County, Taiwan, Republic of China, Postal Code 833

${ }^{15}$ Intensive Care Unit, RIP AS Hospital, Bandar Seri Begawan, Brunei, BA 1715

${ }^{16}$ Intensive Care Unit, Salmaniya Medical Complex, Manama, Kingdom of Bahrain, PO Box 12

${ }^{17}$ Emergency and Critical Care Medicine, University of Tokushima Graduate School, 3-18-15 Kuramoto, Tokushima, 770-8503 Japan

${ }^{18}$ Covidien, Tyco Healthcare Pte Ltd, 103 Penang Road, Visioncrest Commercial, \#10-01, Singapore 238467

${ }^{19}$ Biostatistics Unit, Yong Loo Lin School of Medicine, National University of Singapore, Blk MD 11, \#02-02, Clinical Research

Centre, 10 Medical Drive

Singapore 117597

Correspondence to: Y Koh

yskoh@amc.seoul.kr

Cite this as: BMJ 2011;342:d3245

\section{METHODS}

\section{Study design}

The Management Of Severe sepsis in Asia's Intensive Care unitS (MOSAICS) study is a multinational prospective cohort study. A steering committee of coordinators from various Asian countries, formed in February 2009, invited physicians representing intensive care units in their countries to participate through direct contact, circulated emails, and local meetings. Although participation was voluntary and unfunded, coordinators were encouraged to include as many intensive care units as possible to minimise selection bias.

Participating intensive care units had at least six beds. They could be medical (including respiratory), surgical, or mixed, but not predominantly paediatric, neurosurgical, or coronary intensive care units. All patients admitted to participating units in July 2009 were screened for eligibility; there was no formal sample size calculation. We enrolled all adult patients with severe sepsis, excluding those aged under 21 , transfers from another intensive care unit or hospital, and readmissions to the intensive care unit during the current hospital stay. We included patients regardless of whether they developed severe sepsis or septic shock before admission to the unit or during their stay. The definition of severe sepsis was adapted from the 2001 International Sepsis Definitions Conference and the Surviving Sepsis Campaign ${ }^{32}$ - that is, sepsis with the following organ dysfunctions: hypotension (systolic blood pressure $<90 \mathrm{~mm} \mathrm{Hg}$ or a decrease of $>40 \mathrm{~mm} \mathrm{Hg}$ or mean arterial pressure $<65 \mathrm{~mm} \mathrm{Hg}$ ), hyperlactataemia $(\geq 2 \mathrm{mmol} / \mathrm{L})$, renal (acute increase in serum creatinine concentration to $>176.8 \mathrm{mmol} / \mathrm{L}$ or urine output $<0.5 \mathrm{~mL} / \mathrm{kg} /$ hour for $>2$ hours), lung (acute lung injury with the ratio of the partial pressure of arterial oxygen to the fractional inspired oxygen being $\leq 300 \mathrm{~mm} \mathrm{Hg}$ ), liver (acute increase in bilirubin concentration to $>34.2 \mu \mathrm{mol} / \mathrm{L}$ ), thrombocytopenia (acute decrease to $<100000 / \mu \mathrm{L}$ ), and/or coagulopathy (international normalised ratio $>1.5$ or a partial thromboplastin time $>60 \mathrm{~s})$.

\section{Data collection}

To minimise behavioural change resulting from the study, only the physicians representing each intensive care unit were familiarised with the study design, and no attempts were made to educate the participating centres on the sepsis bundles. Depending on the availability of staff at each intensive care unit, either clinical or research staff entered data on two online data collection forms. The first form, completed before enrolment of patients, recorded organisational characteristics, including the type of intensive care unit (open or closed), specialty (medical, surgical, mixed), number of beds, 24 hour intensivist cover, number of intensivists, ratio of nurses to beds, any accredited intensive care fellowship programme, type of hospital (government non-university, private non-university, university), number of hospital beds, and the country. Data on the facilities, equipment, and protocols in the intensive care units and their affiliated emergency departments to facilitate the bundles were also collected. We defined an intensivist as a physician who has passed intensive care certification examinations or who has completed training in an accredited intensive care fellowship or who treats the total patient and not a single organ system and is recognised by his or her institution as an intensivist.

The second form collected data on patients, including demographics (age and sex), type of diagnosis (medical, scheduled, or unscheduled postoperative), location of patient at diagnosis of severe sepsis (emergency department, ward, intensive care unit), source of infection, organ dysfunction, number of organ failures, the acute physiology and chronic health evaluation (APACHE) II score, mortality in intensive care unit and hospital, length of stay in intensive care unit and hospital, and duration of invasive mechanical ventilation (time from starting ventilation to successful

\begin{tabular}{|c|c|}
\hline Target & Applicable to relevant clinical scenarios \\
\hline \multicolumn{2}{|l|}{ Resuscitation bundle (first 6 hours) } \\
\hline Measure lactate & All patients \\
\hline Blood cultures before antibiotics & All patients \\
\hline $\begin{array}{l}\text { Broad spectrum antibiotics within } 3 \text { hours for emergency department } \\
\text { admissions and } 1 \text { hour for others }\end{array}$ & All patients \\
\hline $\begin{array}{l}\text { Fluids ( } 20 \mathrm{~mL} / \mathrm{kg} \text { of crystalloids or equivalent) with or without } \\
\text { vasopressors }\end{array}$ & $\begin{array}{l}\text { Hypotension or lactate } \geq 4 \mathrm{mmol} / \mathrm{L} \text { (fluids required) with or without septic } \\
\text { shock (hypotension despite initial fluids: vasopressors required) }\end{array}$ \\
\hline $\mathrm{CVP} \geq 8 \mathrm{~mm} \mathrm{Hg}$ & Septic shock or lactate $\geq 4 \mathrm{mmol} / \mathrm{L}$ \\
\hline $\mathrm{ScvO}_{2} \geq 70 \%$ or $\mathrm{SvO}_{2} \geq 65 \%$ & Septic shock or lactate $\geq 4 \mathrm{mmol} / \mathrm{L}$ \\
\hline \multicolumn{2}{|l|}{ Management bundle (first 24 hours) } \\
\hline Low dose steroids administered or considered & Septic shock \\
\hline Drotrecogin alfa (activated) administered or considered & APACHE $I I \geq 25$ or multiorgan failure \\
\hline Glucose $\geq 4.5$ and $\leq 10.0 \mathrm{mmol} / \mathrm{L}$ at $6-24$ hours & All patients \\
\hline Tidal volume $\leq 6 \mathrm{~mL} / \mathrm{kg}$ predicted body weight & ALI/ARDS \\
\hline
\end{tabular}


extubation or breathing with a tracheostomy mask for a continuous period of $\geq 48$ hours). This form also recorded, when clinically appropriate, the achievement of targets in both the resuscitation bundle (lactate measurement, blood cultures, broad spectrum antibiotics, fluids with or without vasopressors, central venous pressure, and central or mixed venous oxygen saturation within six hours after presentation) and the management bundle (steroids, drotrecogin alfa, glucose control, lung protective ventilation within 24 hours) (table 1). The time of presentation, determined from chart review, was defined as the time of presentation to the emergency department with severe sepsis, or the time of diagnosis of severe sepsis for patients who developed severe sepsis in the ward (and other non-emergency department units) or intensive care unit. Given the ongoing controversy regarding the efficacy of steroids and drotrecogin alfa and in line with the definitions of the Surviving Sepsis Campaign, ${ }^{311}$ the targets for these drugs were deemed as met if they were administered or if there was documentation of any discussion that showed that they were considered in the appropriate clinical setting in accordance with the local intensive care unit policy. We set the upper limit for glucose at $10.0 \mathrm{mmol} / \mathrm{L}$ based on the Normoglycaemia in Intensive Care Evaluation and Survival Using Glucose Algorithm Regulation (NICESUGAR) study and the latest recommendations from the Surviving Sepsis Campaign, ${ }^{24}{ }^{26}$ and the lower limit at $4.5 \mathrm{mmol} / \mathrm{L}$ according to van den Berghe et al's protocol and in view of the adverse effects of hypoglycaemia. ${ }^{8}$ The glucose target was considered

Table 2 |Distribution of participating intensive care units and patients by country in study of compliance with Surviving Sepsis Campaign targets

\begin{tabular}{|c|c|c|c|}
\hline $\begin{array}{l}\text { World Bank } \\
\text { analytical income } \\
\text { classification }\end{array}$ & $\begin{array}{l}\text { No of } \\
\text { units }\end{array}$ & $\begin{array}{l}\text { No of enrolled } \\
\text { patients with } \\
\text { severe sepsis }\end{array}$ & $\begin{array}{c}\% \text { of all } \\
\text { admissions in } \\
\text { participating units }\end{array}$ \\
\hline \multicolumn{4}{|c|}{ Low income economies: } \\
\hline Bangladesh & 14 & 65 & 10.8 \\
\hline Nepal & 2 & 62 & 53.9 \\
\hline Vietnam & 3 & 49 & 10.7 \\
\hline \multicolumn{4}{|c|}{ Middle income economies: } \\
\hline China & 40 & 189 & 9.1 \\
\hline Indonesia & 7 & 33 & 6.3 \\
\hline India & 17 & 162 & 5.5 \\
\hline Malaysia & 10 & 120 & 15.7 \\
\hline Pakistan & 3 & 36 & 28.3 \\
\hline \multicolumn{4}{|c|}{ High income economies: } \\
\hline Bahrain & 1 & 11 & 21.2 \\
\hline Brunei & 1 & 12 & 15.2 \\
\hline Hong Kong & 6 & 102 & 17.5 \\
\hline Japan & 1 & 3 & 8.8 \\
\hline Saudi Arabia & 5 & 46 & 12.5 \\
\hline Singapore & 10 & 128 & 25.2 \\
\hline South Korea & 28 & 254 & 10.4 \\
\hline Taiwan & 2 & 13 & 15.3 \\
\hline Total & 150 & 1285 & 10.9 \\
\hline
\end{tabular}

met if all measurements fell within this range. Because of concerns regarding the feasibility of accurate plateau pressure measurements in patients without apnoea, we considered the target for acute lung injury/acute respiratory distress syndrome, defined according to the American-European Consensus Conference, ${ }^{28}$ as being met if the most frequently delivered tidal volume was $\leq 6 \mathrm{~mL}$ per $\mathrm{kg}$ of predicted body weight. ${ }^{9}$ Failure to achieve a target might be because of failure to attempt measurements, or might occur even when attempts were made.

As the online data collection forms were designed to prohibit uncompleted fields, there were no missing data. We did, however, check the collected data for statistical outliers that might suggest entry errors and contacted the intensive care unit representatives for clarification.

\section{Outcome measures}

All patients were followed until discharge from or death in the hospital. The primary outcome measure was compliance with the resuscitation and management bundles. The secondary outcome measure was all cause hospital mortality. Patients who were still in the same hospital on 31 July 2010 (one year from the end of the enrolment period) were deemed survivors. Patients who were discharged home in a terminal state and expected to die within a few hours or days were deemed non-survivors. ${ }^{29}$

\section{Statistical analyses}

Categorical variables are given as number (percentage and $95 \%$ confidence interval for compliance with bundle targets), normally distributed numerical variables as mean (standard deviation), and other numerical variables as median (interquartile range). Categorical variables were analysed with $\chi^{2}$ test or Fisher's exact test. When normality and homogeneity assumptions were satisfied, quantitative variables were compared

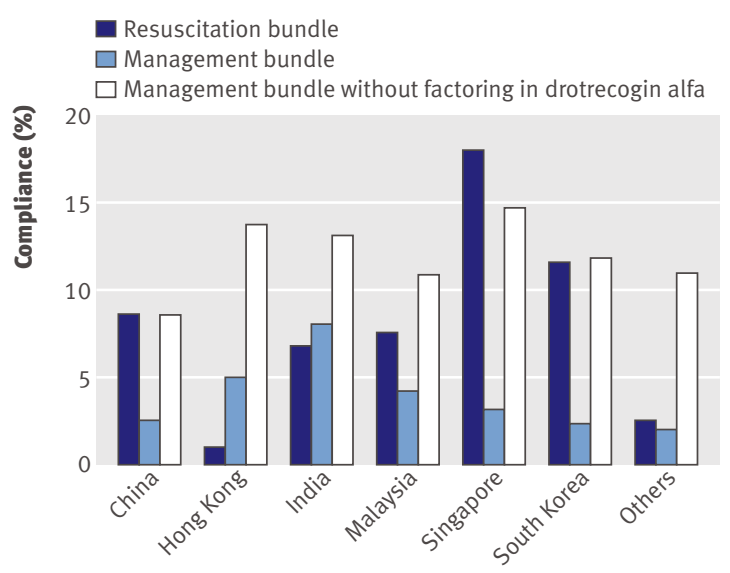

Fig 1 Compliance with resuscitation and management bundles by country. Only countries that enrolled more than 100 patients are shown. Others include Bahrain, Bangladesh, Brunei, Indonesia, Japan, Nepal, Pakistan, Saudi Arabia, Taiwan, and Vietnam. Drotrecogin alfa was unavailable in nine countries, including China, Hong Kong, and South Korea 
Table 3 Baseline characteristics of patients admitted to intensive care units (ICU) in Asia. Figures are numbers (percentages) unless stated otherwise

\begin{tabular}{|c|c|c|c|c|}
\hline Characteristic & $\underset{(n=1285)}{\text { All }}$ & $\begin{array}{c}\text { Survivors } \\
(n=713)\end{array}$ & $\begin{array}{c}\text { Non-survivors } \\
(\mathrm{n}=572)\end{array}$ & Pvalue \\
\hline \multicolumn{5}{|l|}{ Demographics } \\
\hline Mean (SD) age (years) & $59.2(17.8)$ & $57.8(17.8)$ & $61.0(17.5)$ & 0.001 \\
\hline Male & $793(61.7)$ & $428(60.0)$ & $365(63.8)$ & 0.17 \\
\hline \multicolumn{5}{|l|}{ Diagnosis on admission to ICU: } \\
\hline Medical/non-operative & $980(76.3)$ & $543(76.2)$ & $437(76.4)$ & \multirow{3}{*}{0.95} \\
\hline Scheduled/elective postoperative & $90(7.0)$ & $49(6.9)$ & $41(7.2)$ & \\
\hline Unscheduled/emergent postoperative & $215(16.7)$ & $121(17.0)$ & $94(16.4)$ & \\
\hline \multicolumn{5}{|l|}{ Location at diagnosis of severe sepsis: } \\
\hline Emergency department & $490(38.1)$ & $311(43.6)$ & $179(31.3)$ & \multirow{3}{*}{$<0.001$} \\
\hline Ward & $472(36.7)$ & $244(34.2)$ & $228(39.9)$ & \\
\hline ICU & $323(25.1)$ & $158(22.2)$ & $165(28.8)$ & \\
\hline \multicolumn{5}{|l|}{ Source of infection: } \\
\hline Pneumonia/lung & $480(37.4)$ & $273(38.3)$ & $207(36.2)$ & \multirow{11}{*}{0.001} \\
\hline Abdomen other than urinary tract & $271(21.1)$ & $156(21.9)$ & $115(20.1)$ & \\
\hline Urinary tract & $109(8.5)$ & $81(11.4)$ & $28(4.9)$ & \\
\hline Soft tissue/skin & $57(4.4)$ & $28(3.9)$ & $29(5.1)$ & \\
\hline Primary bacteraemia & $26(2.0)$ & $13(1.8)$ & $13(2.3)$ & \\
\hline Meningoencephalitis/nervous system & $27(2.1)$ & $11(1.5)$ & $16(2.8)$ & \\
\hline Bones and joints & $6(0.5)$ & $2(0.3)$ & $4(0.7)$ & \\
\hline Intravascular catheter & $14(1.1)$ & $8(1.1)$ & $6(1.0)$ & \\
\hline Infective endocarditis & $6(0.5)$ & $2(0.3)$ & $4(0.7)$ & \\
\hline Multiple sources & $223(17.4)$ & $102(14.3)$ & $121(21.2)$ & \\
\hline Unknown & $66(5.1)$ & $37(5.2)$ & $29(5.1)$ & \\
\hline \multicolumn{5}{|l|}{ Organ dysfunction on arrival at ICU: } \\
\hline Hypotension or on vasopressors & $939(73.1)$ & $498(69.8)$ & $441(77.1)$ & 0.004 \\
\hline Hyperlactataemia & $466(36.3)$ & $247(34.6)$ & $219(38.3)$ & 0.17 \\
\hline Acute kidney injury & $528(41.1)$ & $246(34.5)$ & $282(49.3)$ & $<0.001$ \\
\hline Acute lung injury & $665(51.8)$ & $347(48.7)$ & $318(55.6)$ & 0.01 \\
\hline Hyperbilirubinaemia & $248(19.3)$ & $127(17.8)$ & $121(21.2)$ & 0.13 \\
\hline Thrombocytopenia & $325(25.3)$ & $151(21.2)$ & $174(30.4)$ & $<0.001$ \\
\hline Coagulopathy & $299(23.3)$ & $139(19.5)$ & $160(28.0)$ & $<0.001$ \\
\hline Mean (SD) No of organ failures & $2.7(1.5)$ & $2.5(1.3)$ & $3.0(1.6)$ & $<0.001$ \\
\hline Mean (SD) APACHE II score & $22.8(8.7)$ & $20.4(7.7)$ & $25.7(9.0)$ & $<0.001$ \\
\hline
\end{tabular}

APACHE II=acute physiology and chronic health evaluation II score during first 24 hours of ICU admission. * Mortality lower for emergency department patients than for ward patients or ICU patients after Bonferroni correction. compliance with the bundles in countries from different income classifications and in centres with and without management protocols.

In assessing achievements for each target, we included only patients with relevant clinical scenarios (table 1). We defined overall compliance with the entire resuscitation and management bundles when all relevant individual targets were met. To identify the independent predictors of mortality, we performed multivariable logistic regression analysis using models that included the achievement of individual bundle targets and all the variables collected for patients' characteristics and organisational characteristics, including the World Bank income classification. We reduced the sources of infection into lung and non-lung to decrease the number of covariates. The first regression model assessed targets required for all patients (lactate measurement, blood cultures, antibiotics, glucose control) and organisational and patient characteristics. Other targets, which were required in some but not all patients - for instance, fluids with or without vasopressors, central venous pressure, central or mixed venous oxygen saturation, steroids, drotrecogin alfa, and tidal volumes (table 1) — were assessed with separate models for each subpopulation. In each model, covariates were classified into target met, target not met, and target not required, as appropriate. We looked for multicollinearity, as well as interactions between bundle targets that were independent predictors of mortality by pairing these targets in the models. Model fit was assessed with the Hosmer-Lemeshow goodness of fit test.

We considered a $\mathrm{P}$ value of $<0.05$ as significant. We used PASW Statistics, version 18.0 (SPSS, Chicago, IL, USA).

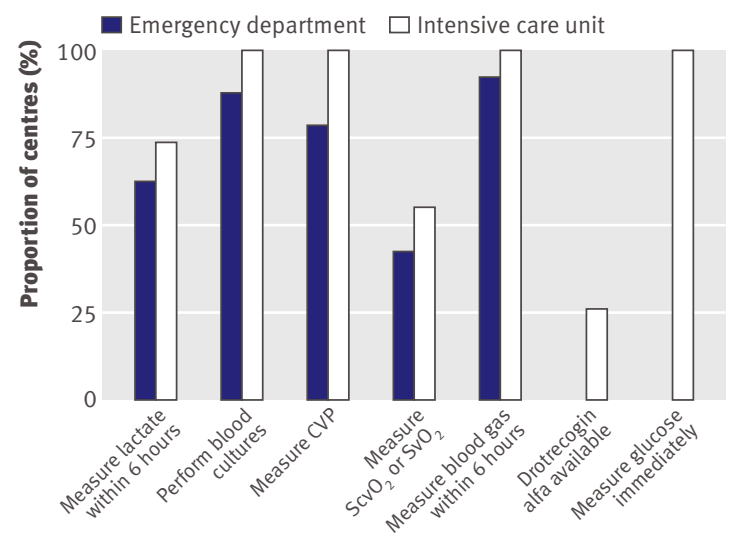

Fig 2 | Proportion of emergency departments and intensive care units with facilities and equipment to perform various functions. Emergency departments not surveyed for drotrecogin alfa and glucose measurements. Fibreoptic catheters with in vivo spectrophotometry or blood gas analysers with co-oximetry are required to measure $\mathrm{ScvO}_{2}$ and $\mathrm{SvO}_{2} \cdot \mathrm{CVP}=$ central venous pressure; $\mathrm{ScvO}_{2}=$ central venous oxygen saturation; $\mathrm{SvO}_{2}=$ mixed venous oxygen saturation 
Table 4|Achievement of Surviving Sepsis Campaign bundle targets in Asian intensive care units. Figures are numbers of patients (percentage, $95 \%$ confidence interval), unless specified otherwise

\begin{tabular}{|c|c|c|c|c|}
\hline Target & All & Survivors & Non-survivors & $P$ value \\
\hline \multicolumn{5}{|l|}{ Resuscitation bundle (first 6 hours) } \\
\hline Measure lactate & $511 / 1285(39.8,37.1$ to 42.5$)$ & $310 / 713(43.5,39.8$ to 47.1$)$ & $201 / 572(35.1,31.2$ to 39.1$)$ & 0.002 \\
\hline Blood cultures before antibiotics & $803 / 1285(62.5,59.8$ to 65.1$)$ & $471 / 713(66.1,62.6$ to 69.5$)$ & $332 / 572(58.0,54.0$ to 62.1$)$ & 0.004 \\
\hline $\begin{array}{l}\text { Broad spectrum antibiotics within } 3 \text { hours for ED admissions and } \\
1 \text { hour for others }\end{array}$ & $821 / 1285(63.9,61.3$ to 66.5$)$ & $478 / 713(67.0,63.6$ to 70.5$)$ & $343 / 572(60.0,60.0$ to 64.0$)$ & 0.009 \\
\hline Fluids with or without vasopressors & $810 / 995(81.4,79.0$ to 83.8$)$ & $437 / 529(82.6,79.4$ to 85.8$)$ & $373 / 466(80.0,76.4$ to 83.7$)$ & 0.30 \\
\hline Fluids for hypotension/hyperlactataemia & $883 / 995(88.7,86.8$ to 90.7$)$ & $480 / 529(90.7,88.3$ to 93.2$)$ & $403 / 466(86.5,83.4$ to 89.6$)$ & 0.03 \\
\hline Vasopressors for persistent hypotension & $722 / 805(89.7,87.6$ to 91.8$)$ & $356 / 405(87.9,84.7$ to 91.1$)$ & $366 / 400(91.5,88.8$ to 94.2$)$ & 0.09 \\
\hline $\mathrm{CVP} \geq 8 \mathrm{~mm} \mathrm{Hg}$ & $345 / 870(39.7,36.4$ to 42.9$)$ & $187 / 444(42.1,37.5$ to 46.7$)$ & $158 / 426(37.1,32.5$ to 41.7$)$ & 0.13 \\
\hline $\mathrm{ScvO}_{2} \geq 70 \%$ or $\mathrm{SvO}_{2} \geq 65 \%$ & $94 / 870(10.8,8.7$ to 12.9$)$ & $55 / 444(12.4,9.3$ to 15.5$)$ & $39 / 426(9.2,6.4$ to 11.9$)$ & 0.13 \\
\hline \multicolumn{5}{|l|}{ Management bundle (first 24 hours) } \\
\hline Low dose steroids considered or administered & $449 / 805(55.8,52.4$ to 59.2$)$ & $211 / 405(52.1,47.2$ to 57.0$)$ & $238 / 400(59.5,54.7$ to 64.3$)$ & 0.04 \\
\hline \multicolumn{5}{|l|}{ Drotrecogin alfa considered or administered: } \\
\hline In all countries & $34 / 1052(3.2,2.2$ to 4.3$)$ & $23 / 559(4.1,2.5$ to 5.8$)$ & $11 / 493(2.2,0.9$ to 3.5$)$ & 0.09 \\
\hline Only in countries with drug & $34 / 411(8.3,5.6$ to 10.9$)$ & $23 / 210(11.0,6.7$ to 15.2$)$ & $11 / 201(5.5,2.3$ to 8.6$)$ & 0.04 \\
\hline Glucose $\geq 4.5$ and $\leq 10.0 \mathrm{mmol} / \mathrm{L}$ at $6-24$ hours & $348 / 1285(27.1,24.7$ to 29.5$)$ & $213 / 713(29.9,26.5$ to 33.2$)$ & $135 / 572(23.6,20.1$ to 27.1$)$ & 0.01 \\
\hline Tidal volume $\leq 6 \mathrm{~mL} / \mathrm{kg}$ PBW & $74 / 630(11.7,9.2$ to 14.3$)$ & $35 / 281(12.5,8.6$ to 16.3$)$ & $39 / 349(11.2,7.9$ to 14.5$)$ & 0.62 \\
\hline \multicolumn{5}{|l|}{ Overall compliance } \\
\hline Entire resuscitation bundle & $98 / 1285(7.6,6.2$ to 9.1$)$ & $74 / 713(10.4,8.1$ to 12.6$)$ & $24 / 572(4.2,2.6$ to 5.8$)$ & $<0.001$ \\
\hline Entire management bundle & $45 / 1285(3.5,2.5$ to 4.5$)$ & $33 / 708(4.6,3.1$ to 6.2$)$ & $12 / 572(2.1,0.9$ to 3.3$)$ & 0.01 \\
\hline Entire management bundle without factoring in drotrecogin alfa & $149 / 1285(11.6,9.9$ to 13.4$)$ & $102 / 713(14.3,11.7$ to 16.9$)$ & $47 / 572(8.2,6.0$ to 10.5$)$ & 0.001 \\
\hline \multicolumn{5}{|l|}{ Median (interquartile range) minutes from diagnosis of severe sepsis to*: } \\
\hline Measure lactate & 147 (36 to 390$)$ & 130 (30 to 336$)$ & 180 (43 to 432$)$ & 0.002 \\
\hline Blood cultures & 89 (30 to 193$)$ & $80(30-189)$ & $99(31$ to 205$)$ & 0.003 \\
\hline Broad spectrum antibiotics & $130(60$ to 275$)$ & $120(60$ to 240$)$ & $150(62$ to 310$)$ & 0.009 \\
\hline $\mathrm{CVP} \geq 8 \mathrm{~mm} \mathrm{Hg}$ & 295 (120 to 540$)$ & 255 (90 to to 488$)$ & 310 (140 to 588$)$ & 0.01 \\
\hline $\mathrm{ScvO}_{2} \geq 70 \%$ or $\mathrm{SvO}_{2} \geq 65 \%$ & 370 (152 to 718$)$ & $360(172$ to 721$)$ & $370(140$ to 710$)$ & 0.74 \\
\hline \multicolumn{5}{|l|}{ Other measurest: } \\
\hline CVP measured in first 6 hours & $601 / 870(69.1,66.0$ to 72.2$)$ & $310 / 444(69.8,65.6$ to 74.1$)$ & $291 / 426(68.3,63.9$ to 72.7$)$ & 0.63 \\
\hline $\mathrm{ScvO}_{2}$ or $\mathrm{SvO}_{2}$ measured in first 6 hours & $213 / 870(24.5,21.6$ to 27.3$)$ & $117 / 444(26.4,22.3$ to 30.5$)$ & $96 / 426(22.5,18.6$ to 26.5$)$ & 0.91 \\
\hline Low dose steroids administered in first 24 hours & $322 / 805(40.0,36.6$ to 43.4$)$ & $138 / 405(34.1,29.5$ to 38.7$)$ & $184 / 400(46.0,41.1$ to 50.9$)$ & 0.001 \\
\hline Drotrecogin alfa administered in first 24 hours & $3 / 1052(0.3,0$ to 0.6$)$ & $1 / 559(0.2,0$ to 0.5$)$ & $2 / 493(0.4,0$ to 1.0$)$ & 0.60 \\
\hline Glucose measured at $6-24$ hours & $1216 / 1285(94.6,93.4$ to 95.9$)$ & $678 / 713(95.1,93.5$ to 96.7$)$ & $538 / 572(94.1,92.1$ to 96.0$)$ & 0.41 \\
\hline
\end{tabular}

$\mathrm{CVP}=$ central venous pressure; $\mathrm{ED}=$ emergency department; $\mathrm{PBW}=$ predicted body weight; $\mathrm{ScvO}_{2}=$ central venous oxygen saturation; $\mathrm{SvO} \mathrm{O}_{2}=$ mixed venous oxygen saturation.

*Time from diagnosis of severe sepsis to achievement of bundle targets recorded only if targets achieved within 24 hours.

†Data for $\mathrm{CVP}, \mathrm{ScvO}_{2}$ and $\mathrm{SvO}_{2}$, and glucose refer to presence of measurements within stipulated time frames regardless of whether clinical targets achieved.

\section{RESULTS}

Sixteen countries and 150 intensive care units participated in the study, enrolling 1285 adult patients (table 2), which accounted for $10.9 \%$ of all intensive care unit admissions during the study period. There were 713 survivors: five were still in the same hospital on 31 July 2010. A total of 572 did not survive: 515 died before discharge and 57 were terminally discharged. The overall hospital mortality was 44.5\% (572/1285), and the intensive care unit mortality was $36.7 \%$ (471/ 1285). The median (interquartile range) length of stay in the intensive care unit and hospital was 7 days (4-12) and 18 days (11-33), respectively, in survivors and 6 days (3-12) and 10 days (4-22), respectively, in nonsurvivors. The duration of mechanical ventilation was 6 days (3-9) in 450 survivors and 4 days (2-10) in 523 non-survivors. Table 3 shows the patients' baseline characteristics. The mean APACHE II score was 22.8.

Table 4 records the achievement of bundle targets, in addition to any attempts to measure central venous pressure, central or mixed venous oxygen saturation, and glucose concentration within the stipulated time frames. The only targets that were achieved more than $50 \%$ of the time were blood cultures, antibiotics, fluids with or without vasopressors, and steroids (table 4). Compliance with the entire resuscitation bundle and management bundle was 7.6\% (98/1285) and $3.5 \%$ (45/1285), respectively. Figure 1 shows the compliance rates of countries that enrolled more than 100 patients. Drotrecogin alfa was unavailable in nine countries (Bangladesh, China, Hong Kong, Indonesia, Japan, Nepal, Pakistan, South Korea, Vietnam); when it was excluded from the management bundle, compliance increased to $11.6 \%(149 / 1285)$.

Table 5 describes the organisational characteristics of the participating centres. Countries with a high income economy, university hospitals, intensive care units with an accredited fellowship programme, and surgical intensive care units were more likely to be compliant with the entire resuscitation bundle. There 
Table 5| Organisational characteristics in Asian intensive care units (ICU) in study of Surviving Sepsis Campaign targets

\begin{tabular}{|c|c|c|c|c|c|c|}
\hline \multirow[b]{2}{*}{ Characteristic } & \multirow{2}{*}{$\begin{array}{l}\text { No (\%) } \\
\text { of ICUs }\end{array}$} & \multirow{2}{*}{$\begin{array}{c}\text { No }(\%) \\
\text { of patients }\end{array}$} & \multicolumn{2}{|c|}{$\begin{array}{l}\text { Compliance with } \\
\text { entire resuscitation } \\
\text { bundle* }\end{array}$} & \multicolumn{2}{|c|}{$\begin{array}{c}\text { Hospital } \\
\text { mortality (\%) }\end{array}$} \\
\hline & & & $\%$ & Pvalue & $\%$ & P value $\ddagger$ \\
\hline \multicolumn{7}{|l|}{ Type of ICU: } \\
\hline Open & $60(40.0)$ & $545(42.4)$ & $8.4 \%$ & \multirow{2}{*}{0.35} & $42.4 \%$ & \multirow{2}{*}{0.19} \\
\hline Closed & $90(60.0)$ & $740(57.6)$ & $7.0 \%$ & & $46.1 \%$ & \\
\hline \multicolumn{7}{|l|}{ ICU specialty: } \\
\hline Medical & $33(22.0)$ & $376(29.3)$ & $11.7 \%$ & \multirow{3}{*}{$<0.0001$} & $39.4 \%$ & \multirow{3}{*}{$<0.001$} \\
\hline Surgical & $14(9.3)$ & $85(6.6)$ & $18.8 \% \S$ & & $29.4 \% \S$ & \\
\hline Mixed & $103(68.7)$ & $824(64.1)$ & $4.6 \%$ & & $48.4 \%$ & \\
\hline \multicolumn{7}{|l|}{ No of ICU beds: } \\
\hline $1-10$ & $33(22.0)$ & $250(19.5)$ & $6.4 \%$ & \multirow{3}{*}{0.32} & $46.8 \%$ & \multirow{3}{*}{0.04} \\
\hline $11-20$ & $74(49.3)$ & $623(48.5)$ & $7.1 \%$ & & $47.0 \%$ & \\
\hline$\geq 21$ & $43(28.7)$ & $412(32.1)$ & $9.2 \%$ & & $39.3 \% \S$ & \\
\hline \multicolumn{7}{|l|}{ No of intensivists $\|:$} \\
\hline $0-3$ & $58(38.7)$ & $501(39.0)$ & $8.4 \%$ & \multirow{3}{*}{0.55} & $47.7 \%$ & \multirow{3}{*}{0.18} \\
\hline 4-6 & $42(28.0)$ & $340(26.5)$ & $7.9 \%$ & & $42.4 \%$ & \\
\hline$\geq 7$ & $50(33.3)$ & $444(34.6)$ & $6.5 \%$ & & $42.6 \%$ & \\
\hline \multicolumn{7}{|l|}{ Intensivist cover: } \\
\hline No 24 hour cover & $51(34.0)$ & $429(33.4)$ & $8.4 \%$ & \multirow{2}{*}{0.46} & $46.4 \%$ & \multirow{2}{*}{0.34} \\
\hline 24 hour cover & $99(66.0)$ & $856(66.6)$ & $7.2 \%$ & & $43.6 \%$ & \\
\hline \multicolumn{7}{|l|}{ Nurse-to-bed ratio in each shift: } \\
\hline 1 nurse: $\geq 3$ beds & $25(16.7)$ & $161(12.5)$ & $8.1 \%$ & \multirow{3}{*}{0.27} & $41.0 \%$ & \multirow{3}{*}{0.28} \\
\hline 1 nurse: 2 beds & $65(43.3)$ & $674(52.5)$ & $8.6 \%$ & & $43.5 \%$ & \\
\hline$\geq 1$ nurse: 1 bed & $60(40.0)$ & $450(35.0)$ & $6.0 \%$ & & $47.3 \%$ & \\
\hline \multicolumn{7}{|l|}{ ICU fellowship programme: } \\
\hline No accredited programme & $58(38.7)$ & $426(33.2)$ & $5.2 \%$ & \multirow{2}{*}{0.019} & $50.0 \%$ & \multirow{2}{*}{0.005} \\
\hline Accredited programme & $92(61.3)$ & $859(66.8)$ & $8.8 \%$ & & $41.8 \%$ & \\
\hline \multicolumn{7}{|l|}{ Type of hospital: } \\
\hline $\begin{array}{l}\text { Government non- } \\
\text { university }\end{array}$ & $46(30.7)$ & $401(31.2)$ & $5.2 \%$ & \multirow{3}{*}{0.010} & $50.9 \% \S$ & \\
\hline Private non-university & $30(20.0)$ & $229(17.8)$ & $6.6 \%$ & & $42.4 \%$ & 0.008 \\
\hline University & $74(49.3)$ & $655(51.0)$ & $9.5 \% \S$ & & $41.4 \%$ & \\
\hline No of hospital beds: & & & & & & \\
\hline $1-500$ & $38(25.3)$ & $303(23.6)$ & $5.6 \%$ & & $43.9 \%$ & \\
\hline $501-1000$ & $60(40.0)$ & $502(39.1)$ & $7.6 \%$ & 0.23 & $48.6 \%$ & 0.04 \\
\hline$\geq 1001$ & $52(34.7)$ & $480(37.4)$ & $9.0 \%$ & & $40.6 \%$ & \\
\hline
\end{tabular}

Country according to 2009 World Bank economy:

\begin{tabular}{|c|c|c|c|c|c|c|}
\hline Low income & $19(12.7)$ & 176 (13.7) & $2.3 \%$ & \multirow{3}{*}{0.002} & $46.6 \%$ & \multirow{3}{*}{0.001} \\
\hline Middle income & 77 (51.3) & $540(42.0)$ & $6.9 \%$ & & $50.0 \%$ & \\
\hline High income & $54(36.0)$ & $569(44.3)$ & $10.0 \% \S$ & & $38.7 \% \S$ & \\
\hline
\end{tabular}

*Shows only associations with compliance with entire resuscitation because there were no associations with compliance with entire management bundle.

†P value for association between each organisational characteristic and compliance with entire resuscitation bundle.

$\ddagger P$ value for association between each organisational characteristic and hospital mortality.

§Applies only to variables with three categories; denotes category that is significantly different compared with grouping of other two categories (after Bonferroni correction).

IRefers to number of intensivists in centre who cover ICU, including on rotational basis.

was no association between organisational characteristics and compliance with the entire management bundle. Table 6 shows the achievement of targets within the resuscitation and management bundles, stratified by the World Bank income classification.

On univariable analysis, meeting the targets for lactate measurement, blood cultures, antibiotics, and glucose control was associated with decreased mortality; meeting the target for low dose steroids was associated with increased mortality (table 4). Organisational factors associated with reduced mortality were high income country, intensive care unit with an accredited fellowship programme, intensive care unit with more than 20 beds, and surgical intensive care unit. Treatment in a government non-university hospital was associated with increased mortality (table 5).

On logistic regression analysis, with models that included the achievement of individual bundle targets and all variables in tables 3 and 5 , the independent predictors of decreased mortality were the achievement of the bundle targets for blood cultures and antibiotics and lower age, lower APACHE II score, and being diagnosed with severe sepsis in the emergency department (table 7). There was no interaction between these targets and no multicollinearity, and the logistic regression models fit well.

Figure 2 shows the proportion of centres with the facilities and equipment available to support the bundles. Many could not measure lactate and central or mixed venous oxygen saturation (using either co-oximetry or dedicated fibreoptic catheters) and did not have access to drotrecogin alfa. Figure 3 shows the existence of management protocols. The presence of such protocols in the intensive care units was associated with a greater achievement of the targets for lactate measurement, central or mixed venous oxygen saturation, steroids, and drotrecogin alfa (fig 4).

\section{DISCUSSION}

\section{Principal findings}

In the Asian centres studied, the overall compliance with the Surviving Sepsis Campaign resuscitation and management bundles was $7.6 \%$ and 3.5\%, respectively. Compliance was considerably higher, but still incomplete, for those components of the bundles that were independently associated with reduced mortality: blood cultures $(62.5 \%)$, broad spectrum antibiotics $(63.9 \%)$, and central venous pressure $\geq 8 \mathrm{~mm} \mathrm{Hg}$ (39.7\%). High income countries, university hospitals, intensive care units with an accredited fellowship programme, and surgical intensive care units were more likely to comply with the resuscitation bundle.

\section{Study strengths and limitations}

The MOSAICS study, a large multinational study of Asian intensive care units, represents a first step towards collaborative Asian intensive care research. To make the study more representative we included a large number of participating centres, though because of a lack of funding this resulted in a need for compromise.

Our study is subject to selection bias and might not fully reflect intensive care throughout Asia. In the absence of Asian or national registries of intensive care units to allow systematic recruitment of units we used a snowball method to identify suitable units, which might have led to the selection of centres with a greater interest in sepsis management. Although we sought to minimise behavioural change in these 
Table $6 \mid$ Achievement of Surviving Sepsis Campaign bundle targets according to World Bank income classification of country. Figures are numbers of patients (percentage, $95 \%$ confidence interval)

\begin{tabular}{|c|c|c|c|c|}
\hline Target & Low income countries & Middle income countries & High income countries & $P$ value \\
\hline \multicolumn{5}{|l|}{ Resuscitation bundle (first 6 hours) } \\
\hline Measure lactate & $25 / 176(14.2,9.0$ to 19.4$)$ & $229 / 540(42.4,38.2$ to 46.6$)$ & $257 / 569(45.2,43.7$ to 51.9$)$ & $<0.001^{\star}$ \\
\hline Blood cultures before antibiotics & $107 / 176(60.8,53.6$ to 68.0$)$ & $281 / 540(52.0,47.8$ to 56.3$)$ & $415 / 569(72.9,69.3$ to 76.6$)$ & $<0.001 \dagger$ \\
\hline $\begin{array}{l}\text { Broad spectrum antibiotics within } 3 \text { hours for ED admissions } \\
\text { and } 1 \text { hour for others }\end{array}$ & $111 / 176(63.1,55.9$ to 70.2$)$ & $335 / 540(62.0,58.0$ to 66.1$)$ & $375 / 569(65.9,62.0$ to 69.8$)$ & 0.40 \\
\hline Fluids with or without vasopressors & $104 / 130(80.0,73.1$ to 86.9$)$ & $340 / 410(82.9,79.3$ to 86.6$)$ & $366 / 455(80.4,76.8$ to 84.1$)$ & 0.58 \\
\hline CVP $\geq 8 \mathrm{~mm} \mathrm{Hg}$ & $38 / 118(32.2,23.8$ to 40.6$)$ & $152 / 367(41.4,36.4$ to 46.5$)$ & $155 / 385(40.3,35.4$ to 45.2$)$ & 0.20 \\
\hline $\mathrm{ScvO}_{2} \geq 70 \%$ or $\mathrm{SvO}_{2} \geq 65 \%$ & $8 / 118(6.8,2.2$ to 11.3$)$ & $47 / 367(12.8,9.4$ to 16.2$)$ & $39 / 385(10.1,7.1$ to 13.1$)$ & 0.16 \\
\hline \multicolumn{5}{|l|}{ Management bundle (first 24 hours) } \\
\hline Low dose steroids considered or administered & $78 / 116(67.2,58.7$ to 75.8$)$ & $195 / 338(57.7,52.4$ to 63.0$)$ & $176 / 351(50.1,44.9$ to 55.4$)$ & $0.004 \ddagger$ \\
\hline Drotrecogin alfa considered or administered & $0 / 140(0)$ & $20 / 448(4.5,2.6$ to 6.4$)$ & $14 / 463(3.0,1.5$ to 4.6$)$ & $0.03 \S$ \\
\hline Glucose $\geq 4.5$ and $\leq 10.0 \mathrm{mmol} / \mathrm{L}$ at 6.24 hours & $56 / 176(31.8,24.9$ to 38.7$)$ & $141 / 540(26.1,22.4$ to 29.8$)$ & $151 / 569(26.5,22.9$ to 30.2$)$ & 0.31 \\
\hline Tidal volume $\leq 6 \mathrm{~mL} / \mathrm{kg}$ PBW & $10 / 101(9.9,4.1$ to 15.7$)$ & $36 / 296(12.2,8.4$ to 15.9$)$ & $28 / 233(12.0,7.8$ to 16.2$)$ & 0.82 \\
\hline \multicolumn{5}{|l|}{ Overall compliance } \\
\hline Entire resuscitation bundle & $4 / 176(2.3,0.1$ to 4.5$)$ & $37 / 540(6.9,4.7$ to 9.0$)$ & $57 / 569(10.0,7.6$ to 12.5$)$ & $0.002 \pi$ \\
\hline Entire management bundle & $4 / 176(2.3,0.1$ to 4.5$)$ & $25 / 540(4.6,2.9$ to 6.4$)$ & $16 / 569(2.8,1.5$ to 4.2$)$ & 0.16 \\
\hline
\end{tabular}

$\mathrm{CVP}=$ central venous pressure; $\mathrm{ED}=$ emergency department; $\mathrm{PBW}=$ predicted body weight; $\mathrm{ScvO}_{2}=$ central venous oxygen saturation; $\mathrm{SvO} \mathrm{O}_{2}=\mathrm{mixed}$ venous oxygen saturation.

*Target achieved more often in high $v$ low income countries and in middle $v$ low income countries.

†Target achieved more often in high $v$ low income countries and in high $v$ middle income countries.

$\ddagger$ Target achieved more often in low $v$ high income countries.

$\S$ Target achieved more often in middle $v$ low income countries.

ๆTarget for entire resuscitation bundle achieved more often in high $v$ low income countries.

centres because of the study by limiting the number of physicians with in depth knowledge of the study design, we cannot exclude the presence of a Hawthorne effect. While there was a good representation of countries across the World Bank income categories, ${ }^{30}$ intensive care units with less than six beds were excluded, many of the United Nations' Least Developed Countries did not participate, ${ }^{31}$ and university hospitals accounted for $50 \%$ of centres. The latter two points stand out when one considers the fact that all participating units could perform blood cultures, measure central venous pressure, arterial blood gases, glucose, and carry out the necessary chemical analyses to calculate the APACHE II score, all of which are a relative luxury in the most resource poor areas in Asia. Importantly, the number of patients in

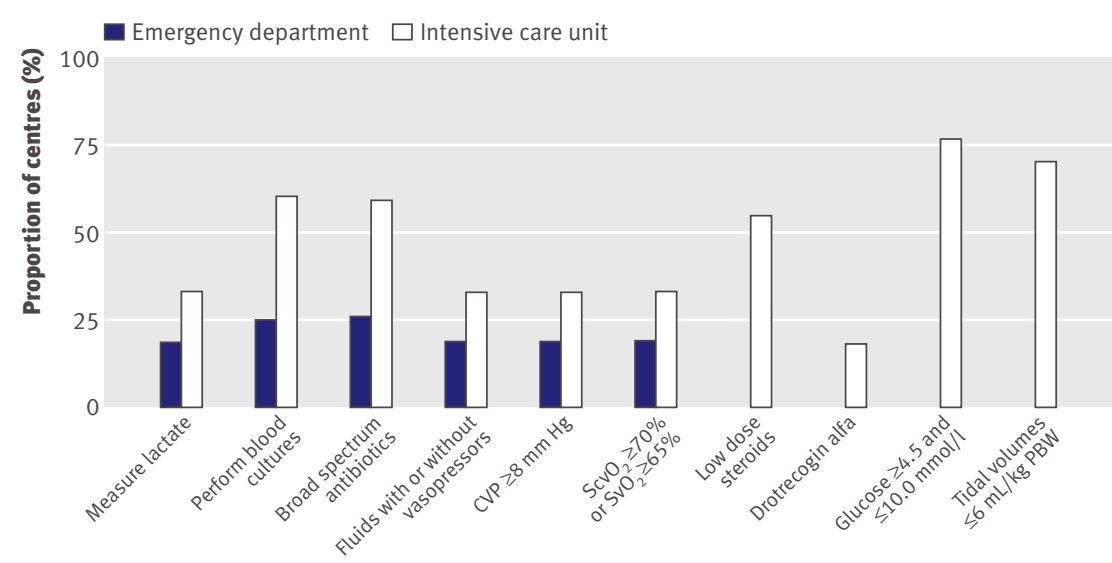

Fig 3 | Proportion of emergency departments and intensive care units with protocols to achieve individual bundle targets. Emergency departments not surveyed for steroids, drotrecogin alfa, glucose measurements, and tidal volumes. $C V P=$ central venous pressure; $P B W=$ predicted body weight; $\mathrm{ScvO}_{2}=$ central venous oxygen saturation; $\mathrm{SvO}_{2}=$ mixed venous oxygen saturation the study sample was not proportionate to the population of the countries taking part in the study. About three quarters of the patients were enrolled in six of the 16 countries. While some of these countries have large populations (such as China and India), others (such as Hong Kong and Singapore) have relatively small populations, and results from these countries would have had a disproportionate effect on overall compliance (fig 1). Enrolment rates within centres differed across countries possibly because of heterogeneity in the nature of intensive care units and healthcare systems. Previous data have shown that the prevalence of infection in intensive care units is higher in those countries that spend a smaller proportion of gross domestic product on healthcare. ${ }^{32}$ The inability of many centres to measure lactate (fig 2) could also have introduced selection bias as patients who would have fulfilled criteria for severe sepsis based on hyperlactataemia, in the absence of other organ failures, would not have been enrolled in these centres. While selection bias is likely, we note that severe sepsis accounted for $10.9 \%$ of all admissions to intensive care units in our study, a rate that mirrors the $11 \%$ seen in the United States ${ }^{2}$ and Australia and New Zealand. ${ }^{33}$ The net effect of the selection bias could be an overestimate of compliance with the Surviving Sepsis Campaign bundles. With this in mind, and in view of the heterogeneity of the study population, we presented compliance rates stratified according to the participating countries' World Bank income classification to provide a clearer overview of sepsis management in Asian countries.

According to the definitions of the Surviving Sepsis Campaign, mere measurement of central venous pressure, central or mixed venous oxygen saturation, and 
Table $7 \mid$ Variables independently associated with hospital mortality on logistic regression analysis in study of Surviving Sepsis Campaign targets in patients admitted to Asian intensive care units (ICU)

\begin{tabular}{llc}
$\begin{array}{l}\text { Variable* } \\
\text { Patients' characteristics: }\end{array}$ & $\begin{array}{c}\text { Adjusted odds ratio } \\
(95 \% \mathrm{Cl})\end{array}$ & P value \\
\hline Age & $0.98+(0.98$ to 0.99$)$ & $<0.001$ \\
\hline APACHE II score & $0.93 \ddagger(0.92$ to 0.95$)$ & $<0.001$ \\
\hline \multicolumn{2}{l}{ Location at diagnosis of severe sepsis: } \\
\hline ED $v$ ward & $0.68(0.49$ to 0.93$)$ & 0.01 \\
\hline ED $v$ ICU & $0.58(0.40$ to 0.83$)$ & 0.003 \\
\hline Achievement of bundle targets: & \\
\hline Blood cultures & $0.72(0.54$ to 0.95$)$ & 0.02 \\
\hline Broad spectrum antibiotics & $0.76(0.58$ to 0.99$)$ & 0.049 \\
\hline CVP $\geq 8 \mathrm{~mm} \mathrm{Hg}$ & $0.67(0.47$ to 0.94$)$ & 0.02 \\
\hline
\end{tabular}

APACHE II=acute physiology and chronic health evaluation score during first 24 hours of ICU admission; CVP=central venous pressure; $\mathrm{ED}=$ emergency department.

*For model assessing blood culture, antibiotics, age, APACHE II score, and location at diagnosis of severe sepsis, with Hosmer-Lemeshow test for goodness of fit test, $X^{2}=11.434, d f=8, P=0.18$. For model assessing CVP, $X^{2}=5.025, d f=8, P=0.76$.

$\dagger$ Per year decrease.

$\ddagger$ Per point decrease.

glucose does not qualify as compliance unless the predefined clinical targets are met. ${ }^{3}$ While these targets can easily be reached in mild disease, centres might not achieve them and hence are deemed non-compliant in sicker patients, not because of a failure to attempt it but because of the sheer severity of illness. In response, some investigators have recorded any attempt to measure central venous pressure and centra or mixed venous oxygen saturation as being guideline compliant, regardless of the values achieved. ${ }^{12}{ }^{13}$ This alternative method, however, does not necessarily reflect any attempt to optimise preload or tissue oxygenation and will probably result in an overestimation of compliance rates. This is illustrated by our data, which show a large difference between the frequency of measuring these parameters versus actual achievement of clinical thresholds. As a result, we and others have

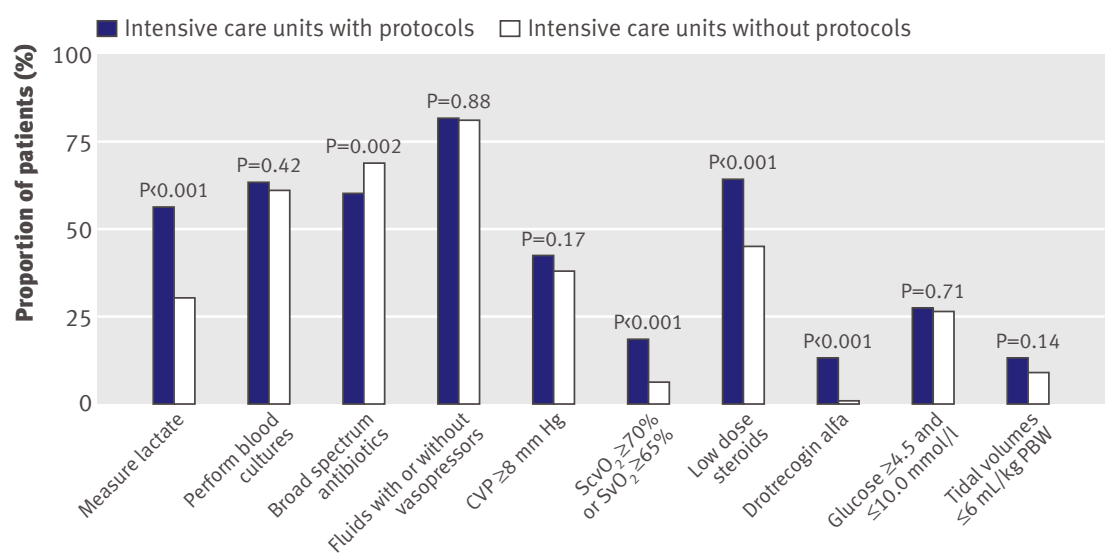

Fig $4 \mid$ Achievement of specific bundle targets in intensive care units with and without corresponding protocols. $\mathrm{CVP}=$ central venous pressure; $\mathrm{PBW}=$ predicted body weight; $\mathrm{ScvO}_{2}=$ central venous oxygen saturation; $\mathrm{SvO}_{2}=$ mixed venous oxygen saturation closely followed the campaign's original definitions of compliance. $^{31115}$

Other study limitations include the need to balance comprehensive data collection versus simplicity required to encourage participation. We omitted culture results as Asian microbiological data are already available from a recent multinational study. ${ }^{32} \mathrm{We}$ recorded tidal volumes instead of complex plateau pressure measurements, choosing a threshold of $\leq 6 \mathrm{~mL} / \mathrm{kg}$ of predicted body weight to define compliance as per the Surviving Sepsis Campaign recommendations. ${ }^{925}$ Given the logistical difficulties and questionable relevance of 28 day mortality, ${ }^{34}$ like other bundle studies, ${ }^{11}{ }^{15}$ we recorded hospital mortality, which is affected by variable thresholds for hospital discharge. Lastly, though we did not systematically check data accuracy, we did design the online data entry forms to disallow missing fields and contacted intensive care unit representatives for clarification of any outlying data.

\section{Comparisons with other studies and implications}

Overall compliance with the resuscitation (7.6\%) and management bundles (3.5\%) was lower in our study than in other multicentre cohorts. ${ }^{11-15}$ Recent compliance rates to adaptations of the resuscitation bundle were 10.0\% in Spain, ${ }^{11} 10.7 \%$ in France, ${ }^{12} 12.1 \%$ in Portugal, ${ }^{13}$ and $14 \%$ in the United Kingdom..${ }^{14}$ A multinational survey by the Surviving Sepsis Campaign, which included countries in Europe and North and South America, found a compliance rate of $31.3 \% .^{15}$ Compliance rates with the management bundle were $15.7 \%$ in Spain, ${ }^{11}$ and $36.1 \%$ in the multinational survey. ${ }^{15}$ Specifically, while compliance with those bundle elements that we found were independently associated with mortality (blood cultures, antibiotics, and central venous pressure) was comparable with that in other multicentre studies, achievement of individual targets for glucose control $(27.1 \%)$ and drotecogin alfa $(3.2 \%)$ was poorer. Achievement of targets for tidal volumes in acute lung injury/acute respiratory distress syndrome was also lower in our study $(11.7 \%)$ than in a 2004 international survey that included two Asian countries (19.6\%). ${ }^{35}$

Hospital mortality was $44.5 \%$ in our cohort, which compares poorly with the $38 \%$ mortality reported in a study from Australia and New Zealand, even after taking into account our slightly higher APACHE II score (22.8 v 21). ${ }^{36}$ Baseline mortality in a Spanish cohort with a mean APACHE II score of 20.5 was $42.5 \%$, but improved to $38.7 \%$ after an educational programme designed to increase compliance with the sepsis bundles. ${ }^{11}$ In a French cohort improved compliance with the bundles was associated with a decrease in mortality from $39.6 \%$ to $27.4 \% .{ }^{12}$ The multinational survey by the Surviving Sepsis Campaign showed a similar reduction in mortality from $37 \%$ to $30.8 \%$ with increased compliance. ${ }^{15}$ Furthermore, a meta-analysis of eight smaller studies found that bundle use was associated with improved survival. ${ }^{10}$ Taken together, these 


\section{WHAT IS ALREADY KNOWN ON THIS TOPIC}

Severe sepsis is a prevalent, costly, and often fatal condition

To improve outcomes in severe sepsis, the Surviving Sepsis Campaign recommends a 6 hour resuscitation bundle and a 24 hour management bundle

\section{WHAT THIS STUDY ADDS}

In Asian centres, overall compliance with the resuscitation and management bundles is only $7.6 \%$ and $3.5 \%$, respectively

High income countries, university hospitals, intensive care units with an accredited fellowship programme, and surgical intensive care units are more likely to be compliant with the resuscitation bundle

Given the resource limitations in Asia, the most appropriate strategy to improve outcomes in severe sepsis might be to focus on ensuring early administration of antibiotics after blood cultures and appropriate fluid treatment data suggest that more should be done to improve compliance with the sepsis bundles in Asia.

Nonetheless, implementation of whole bundles might be no more effective than implementation of selected components. The only targets that were independently associated with reduced mortality were blood culture, antibiotics, and central venous pressure in our study and blood culture, antibiotics, drotrecogin alfa, glucose control, and plateau pressure in the Surviving Sepsis Campaign's multinational study. ${ }^{15}$ Indeed, concerns remain about the science behind the sepsis bundles, ${ }^{37}$ and prompt treatment with antibiotics is the only target that is consistently linked with survival in multiple bundle studies. ${ }^{10153}$ The use of measurements of central venous pressure to guide fluid resuscitation remains controversial. ${ }^{39}$ Our finding that achieving a central venous pressure of $\geq 8 \mathrm{~mm} \mathrm{Hg}$ can improve survival does not necessarily mandate such measurements but could suggest that aggressive fluid resuscitation is often required in patients with severe sepsis. Achievement of the target for fluids was associated with decreased mortality on univariable analysis, although fluids with or without vasopressors were not linked with mortality on logistic regression analysis. This could be because the latter target is a composite of two dichotomous variables rather than the exact volume of fluid administered. In our study, although considered or administered more often in non-survivors, steroids were not associated with mortality on multivariable analysis, in keeping with the findings of a large randomised controlled trial of corticosteroid treatment for septic shock. ${ }^{22}$ The effectiveness of other components of the bundles has also been questioned, with another large randomised controlled trial suggesting that intensive insulin treatment could be harmful, ${ }^{24}$ and ongoing studies are looking at early goal directed treatment and drotrecogin alfa. ${ }^{10}$ Despite these doubts, proponents of bundles might advocate their implementation based on the premise that the total is greater than the sum of the parts. ${ }^{40}$ This premise would be supported by evidence of an interaction between bundle components on logistic regression, but we found no such interaction. Meanwhile, observational data that suggested a lower mortality when whole bundles were fulfilled remain confounded because it is easier to achieve all targets in less sick patients. ${ }^{101316}$

Concentrating on selected bundle targets might therefore be required in resource constrained Asia. ${ }^{2030}$ Barriers to adherence to clinical practice guidelines have been categorised into three areas: knowledge, attitudes, and behaviour. ${ }^{18}$ Although we did not assess knowledge and attitudes, there are no concerted national efforts to promote the sepsis bundles in the countries participating in our study and a lack of awareness might have affected compliance. In addition clinicians' behaviours are affected by the availability of resources. Protocols alone are insufficient to ensure compliance. Full implementation of the sepsis bundles is possible only with considerable resources (see appendix 1 on bmj.com), which many of the participating centres lack. ${ }^{41}$ Compliance with the resuscitation bundle was the lowest in low and middle income economies, and Asia is home to some of the world's poorest nations. ${ }^{30}$ Some emergency departments could not perform blood cultures or measure central venous pressure or blood gases, and many emergency departments and intensive care units could not measure lactate and central or mixed venous oxygen saturation. Drotrecogin alfa was not available in participating intensive care units in nine countries. We did not collect data on the availability of dobutamine and blood, which could be required to optimise central or mixed venous oxygen saturation, but it is conceivable that these might also be in short supply in poorer settings. In sum, taking into account selection bias including the under-representation of the United Nations' Least Developed Countries and the overrepresentation of university centres in our study, true compliance to the sepsis bundles is likely to be even lower than our data suggest. We suggest that given the resource limitations in Asia, the most appropriate strategy might be to focus on ensuring early administration of antibiotics after blood cultures and appropriate fluid treatment.

\section{Conclusions}

Compliance with the Surviving Sepsis Campaign's resuscitation and management bundles for severe sepsis in adult patients is generally poor in much of Asia. High income countries and academic centres are more compliant with the resuscitation bundle. Mortality was high in our cohort, suggesting that more work needs to be done to improve the outcome of severe sepsis in Asia. Achievement of targets for blood cultures, antibiotics, and central venous pressure was independently associated with improved survival. These findings have important implications for healthcare policy makers.

\section{The MOSAICS Study Group}

Steering and writing committee: Jason Phua, Younsuck Koh, Bin Du, Yao-Qing Tang, Jigeeshu V Divatia, Cheng Cheng Tan, Charles

D Gomersall, Mohammad Omar Faruq, Babu Raja Shrestha, Gia Binh 
Nguyen, Yaseen M Arabi, Nawal Salahuddin, Bambang Wahyuprajitno, Mei-Lien Tu, Ahmad Yazid Haji Abd Wahab, Akmal A Hameed, Masaji Nishimura, Mark Procyshyn, Yiong Huak Chan. Data and clinical coordination: Xiang-Yu Zhang, Bisharad M Shrestha, Abdul Diab, Meng-Chih Lin. Participating centres are shown in appendix 2 on bmj.com

We thank all staff in the intensive care units and hospitals that participated in this study.

Contributors: JP and YK conceived the study. All authors participated in the design of the study. YK, BD, Y-QT, JVD, JP, CCT, CDG, MOF, BRS, GBN YMA, NS, BW, M-LT, AYHAW, AAH, and MN coordinated patient enrolment and data collection for their respective countries. MP managed the data collection website. JP and YHC performed the statistical analyses. JP and CDG wrote the first draft of the report. All authors revised the text and approved the final version of the report. All authors had full access to all of the data (including statistical reports and tables) in the study and can take responsibility for the integrity for the data and the accuracy of the data analysis. YK is guarantor.

Funding: JP, YK, BD, JVD, CCT, BW, M-LT, and MN are directors of the Asia Ventilation Forum, an independent non-profit working group. This study was conducted under the auspices of the Asia Ventilation Forum. A steering committee meeting was held in April 2009 in conjunction with the Asia Ventilation Forum Annual Scientific Meeting. Aside from support for meeting room expenses by Covidien, the study was unfunded. Access to the data collection website was provided by Covidien. Covidien had no role in the collection, analysis, and interpretation of the data, in the writing of the report, and in the decision to submit the article for publication. Competing interests: All authors have completed the ICMJE uniform disclosure form at www.icmje.org/coi_disclosure.pdf (available on request from the corresponding author) and declare: JP, YK, BD, JVD, CCT, $B W, M-L T$, and $M N$ are directors of the Asia Ventilation Forum and have received travel support for the Asia Ventilation Forum Board of Directors meeting as well as honorariums for lectures in the Asia Ventilation Forum Annual Scientific Meeting from Covidien; MP is an employee of Covidien but contributes to the work in his own personal capacity.

Ethical approval: This study was approved by institutional review boards according to local regulations in each participating centre and country. Data sharing: Technical appendix and statistical code are available from the corresponding author at yskoh@amc.seoul.kr. Data are available from the MOSAICS Study Group through the corresponding author subject to an end user authorisation agreement.

1 Lever A, Mackenzie I. Sepsis: definition, epidemiology, and diagnosis. BMJ 2007;335:879-83.

2 Angus DC, Linde-Zwirble WT, Lidicker J, Clermont G, Carcillo J, Pinsky MR. Epidemiology of severe sepsis in the United States: analysis of incidence, outcome, and associated costs of care. Crit Care Med 2001;29:1303-10.

3 Surviving Sepsis Campaign. 2011. www.survivingsepsis.org/Pages/ default.aspx

4 Kumar A, Roberts D, Wood KE, Light B, Parrillo JE, Sharma S, et al. Duration of hypotension before initiation of effective antimicrobial therapy is the critical determinant of survival in human septic shock. Crit Care Med 2006;34:1589-96.

5 Rivers E, Nguyen B, Havstad S, Ressler J, Muzzin A, Knoblich B, et al. Early goal-directed therapy in the treatment of severe sepsis and septic shock. N Engl J Med 2001;345:1368-77.

6 Annane D, Sebille V, Charpentier C, Bollaert PE, Francois B, Korach JM, et al. Effect of treatment with low doses of hydrocortisone and fludrocortisone on mortality in patients with septic shock. JAMA 2002;288:862-71.

7 Bernard GR, Vincent JL, Laterre PF, LaRosa SP, Dhainaut JF, Lopez-Rodriguez A, et al. Efficacy and safety of recombinant human activated protein $\mathrm{C}$ for severe sepsis. N Engl I Med 2001;344:699-709.

8 Van den Berghe G, Wouters P, Weekers F, Verwaest C, Bruyninckx F, Schetz $\mathrm{M}$, et al. Intensive insulin therapy in the critically ill patients. $N$ Engl I Med 2001;345:1359-67.

9 Ventilation with lower tidal volumes as compared with traditional tidal volumes for acute lung injury and the acute respiratory distress syndrome. The Acute Respiratory Distress Syndrome Network. N Engl J Med 2000;342:1301-8.

10 Barochia AV, Cui X, Vitberg D, Suffredini AF, O'Grady NP, Banks SM, et al. Bundled care for septic shock: an analysis of clinical trials. Crit Care Med 2010;38:668-78

11 Ferrer R, Artigas A, Levy MM, Blanco J, Gonzalez-Diaz G, Garnacho-Montero J, et al. Improvement in process of care and outcome after a multicenter severe sepsis educational program in Spain. JAMA 2008;299:2294-303.
12 Lefrant JY, Muller L, Raillard A, Jung B, Beaudroit L, Favier L, et al. Reduction of the severe sepsis or septic shock associated mortality y reinforcement of the recommendations bundle: a multicenter study. Ann Fr Anesth Reanim 2010;29:621-8.

13 Cardoso T, Carneiro AH, Ribeiro O, Teixeira-Pinto A, Costa-Pereira A Reducing mortality in severe sepsis with the implementation of a core 6-hour bundle: results from the Portuguese communityacquired sepsis study (SACiUCl study). Crit Care 2010;14:R83.

14 Daniels R, Nutbeam T, McNamara G, Galvin C. The sepsis six and the severe sepsis resuscitation bundle: a prospective observational cohort study. Emerg Med J 2010: published online 29 October.

15 Levy MM, Dellinger RP, Townsend SR, Linde-Zwirble WT, Marshall JC, Bion J, et al. The Surviving Sepsis Campaign: results of an international guideline-based performance improvement program targeting severe sepsis. Crit Care Med 2010;38:367-74.

16 Castellanos-Ortega A, Suberviola B, Garcia-Astudillo LA, Holanda MS, Ortiz F, Llorca J, et al. Impact of the Surviving Sepsis Campaign protocols on hospital length of stay and mortality in septic shock patients: results of a three-year follow-up quasi-experimental study. Crit Care Med 2010;38:1036-43.

17 Gao F, Melody T, Daniels DF, Giles S, Fox S. The impact of compliance with 6-hour and 24-hour sepsis bundles on hospital mortality in patients with severe sepsis: a prospective observational study. Crit Care 2005;9:R764-70.

18 Cabana MD, Rand CS, Powe NR, Wu AW, Wilson MH, Abboud PA, et al. Why don't physicians follow clinical practice guidelines? A framework for improvement. JAMA 1999;282:1458-65.

19 Fowler RA, Adhikari NK, Bhagwanjee S. Clinical review: critical care in the global context-disparities in burden of illness, access, and economics. Crit Care 2008;12:225.

20 Dunser MW, Baelani I, Ganbold L. A review and analysis of intensive care medicine in the least developed countries. Crit Care Med 2006;34:1234-42.

21 Du B, Xi X, Chen D, Peng J. Clinical review: critical care medicine in mainland China. Crit Care 2010;14:206.

22 Sprung CL, Annane D, Keh D, Moreno R, Singer M, Freivogel K, et al. Hydrocortisone therapy for patients with septic shock. N Engl J Med 2008;358:111-24.

23 Eichacker PQ, Natanson C, Danner RL. Surviving sepsis-practice guidelines, marketing campaigns, and Eli Lilly. N Engl / Med 2006;355:1640-2

24 Finfer S, Chittock DR, Su SY, Blair D, Foster D, Dhingra V, et al. Intensive versus conventional glucose control in critically ill patients. N Engl J Med 2009;360:1283-97.

25 Dellinger RP, Levy MM, Carlet JM, Bion J, Parker MM, Jaeschke R, et al. Surviving Sepsis Campaign: international guidelines for management of severe sepsis and septic shock: 2008. Crit Care Med 2008;36:296-327.

26 Dellinger RP, Surviving Sepsis Campaign Executive Committee. Surviving Sepsis Campaign statement on glucose control in severe sepsis. 2009. www.learnicu.org/Docs/Guidelines/ GlucoseControlSepsis.pdf.

27 Levy MM, Fink MP, Marshall JC, Abraham E, Angus D, Cook D, et al. 2001 SCCM/ESICM/ACCP/ATS/SIS International Sepsis Definitions Conference. Crit Care Med 2003;31:1250-6.

28 Bernard GR, Artigas A, Brigham KL, Carlet J, Falke K, Hudson L, et al. The American-European Consensus Conference on ARDS. Definitions, mechanisms, relevant outcomes, and clinical trial coordination. Am J Respir Crit Care Med 1994;149:818-24.

29 Huang YC, Huang SJ, Ko WJ. Going home to die from surgical intensive care units. Intensive Care Med 2009;35:810-5.

30 World Bank. Data and statistics: country classification 2009. 2011 http://web.worldbank.org/WBSITE/EXTERNAL/DATASTATISTICS/0, contentMDK:20421402 pagePK:64133150 piPK:64133175 theSitePK:239419,00.html.

31 United Nations Office of the High Representative for the Least Developed Countries, Landlocked Developing Countries and the Small Island Developing States (UN-OHRLLS). Least developed countries: country profiles. 2011. www.un.org/ohrlls/.

32 Vincent JL, Rello J, Marshall J, Silva E, Anzueto A, Martin CD, et al. International study of the prevalence and outcomes of infection in intensive care units. JAMA 2009:302:2323-9.

33 Finfer S, Bellomo R, Lipman J, French C, Dobb G, Myburgh J. Adultpopulation incidence of severe sepsis in Australian and New Zealand intensive care units. Intensive Care Med 2004:30:589-96.

34 Marshall JC, Vincent JL, Guyatt G, Angus DC, Abraham E, Bernard G, et al. Outcome measures for clinical research in sepsis: a report of the 2nd Cambridge Colloquium of the International Sepsis Forum. Crit Care Med 2005;33:1708-16.

35 Esteban A, Ferguson ND, Meade MO, Frutos-Vivar F, Apezteguia C, Brochard $\mathrm{L}$, et al. Evolution of mechanical ventilation in response to clinical research. Am J Respir Crit Care Med 2008;177:170-7. 
36 Dulhunty JM, Lipman J, Finfer S. Does severe non-infectious SIRS differ from severe sepsis? Results from a multi-centre Australian and New Zealand intensive care unit study. Intensive Care Med 2008;34:1654-61.

37 Finfer S. The Surviving Sepsis Campaign: robust evaluation and highquality primary research is still needed. Crit Care Med 2010;38:683-4.

38 Ferrer R, Artigas A, Suarez D, Palencia E, Levy MM, Arenzana A, et al. Effectiveness of treatments for severe sepsis: a prospective, multicenter, observational study. Am J Respir Crit Care Med 2009;180:861-6.
39 Marik PE, Baram M, Vahid B. Does central venous pressure predict fluid responsiveness? A systematic review of the literature and the tale of seven mares. Chest 2008;134:172-8.

40 Resar R, Pronovost P, Haraden C, Simmonds T, Rainey T, Nolan T. Using a bundle approach to improve ventilator care processes and reduce ventilator-associated pneumonia. It Comm J Qual Patient Saf 2005;31:243-8.

41 Teles JM, Silva E, Westphal G, Filho RC, Machado FR. Surviving sepsis campaign in Brazil. Shock 2008;30(suppl 1):47-52.

Accepted: 25 March 2011 